\title{
Research Utilization: An Experience of National Study on Merging Smoking Cessation With Drug Abuse Treatment in Welfare Organization, Iran 2017
}

\author{
Mohsen Roshanpajouh, MD $^{2^{*}}$, Gholamreza Heydari, MD, MPH, Ph.D. ${ }^{1}$ \\ Behroz Almasinia ${ }^{1}$, Parizad Sinaee, Ph.D. ${ }^{1}$, Mehri Amiri, Ph.D. ${ }^{2}$ \\ ${ }^{2 *}$ Addiction Researches Department, School of Behavioral Sciences and Mental Health, Iran University of \\ Medical Sciences. (IUMS) Tehran, Iran \\ ${ }^{1}$ Tobacco Prevention and Control Research Center(TPCRC), National \\ Research Institute of TB and Lung Diseases (NRITLD), Shahid Beheshti \\ University of Medical Sciences, Tehran, Iran \\ ${ }^{2}$ State Welfare Organization, Tehran, Iran
}

Abstract:

Background: Many of opium abusers are a tobacco smoker and would like to quit smoking but there is a challenge to accept that smoking cessation can be added to treatment for drug abuse. The aim of this study was to merging smoking cessation with drug abuse treatment nationally as research utilization based on finding from a randomized clinical trial on dual addiction in Tehran, 2012.

Method: This was a cross sectional study of merging quit smoking intervention with behavioral therapy and medication in 24 drug abuse treatment centers at welfare organization in 6 districts of Iran in 2017.

Results: More than 2000 male clients were involved with age over $18.78 \%$ of them were satisfied with this new treatment and after 6 months $23 \%$ of them quit smoking, in $46 \%$ smoking less than half amount at first was seen and $31 \%$ were smoker while they had their maintenance medication on addiction.

Conclusion: Research utilization of smoking cessation intervention was acceptable and can have a significant impact on the general health of drug abusers.

Key words: smoking, cessation, drug abuse, treatment

\section{BACKGROUND}

Nicotine addiction is rarely regarded with the same urgency as drug narcotics abuse in the scope of public health [1]. Yet, with the rise of cigarette consumption within developing countries reaching epidemic levels, the specter of widespread smoking-related morbidity and mortality remains a looming public health crisis [2]. It is predicted that by 2030 over $80 \%$ of smoking-related deaths worldwide will occur in countries with low or average income [3]. In the Islamic Republic of Iran, conservative estimates place the over prevalence at 16\% [4]. Recent data show that $80.6 \%$ of current smokers first experimented before the age of 15 years (around the average age of narcotics experimentation). It is estimated that $10.3 \%$ of young people smoke habitually [5].

Over the past two decades the demographics of drug abuse in the Islamic Republic of Iran have been similarly changing. Whereas the average age of addiction used to fall between 25 and 29 years, that figure is now between 10 and 19 years [6]. Today, the average drug abuser is younger and less financially stable. Couple this trend with an over all younger population in the Islamic Republic of Iran and the number of drug abusers 
Research Utilization: An Experience of National Study on Merging Smoking Cessation With Drug Abuse Treatment in Welfare Organization, Iran 2017

is burgeoning. The behavioral connections between smoking and drug use become important as the mean age of introduction for tobacco and narcotics converge.

The intersection of these "dual addictions" is particularly problematic for Iranian health officials. Tobacco usage is very common among those addicted to drugs and especially among opiate abusers, who constitute the majority of the Islamic Republic of Iran's addict population. Among this group 60\%- 90\% are smokers [7]. The phenomenon of dual addictions has been noted in studies around the world. In a study conducted in the north-eastern United States of America, 83\% of those who receive methadone treatment are also addicted to smoking cigarettes [8]. Data from China's National Institute of Addiction show that cigarette smoking is prevalent among an astounding $99.4 \%$ of opiate addicts [9]. The principle explanation for the high prevalence of nicotine addiction among opium addicts is the neurochemical relatedness of the addictions. Research has shown that nicotine addiction is controlled by the same chemical nerve receptors that control addiction to opium derivatives [10]. Those undergoing methadone treatment report an intensified craving for nicotine [11]. Stein et al. [12] conducted a series of experiments in 2006 and 2007 that suggest there is a significant relationship between nicotine replacement therapy and a reduction in both smoking and drug abuse. Reid et al. in 2008 [13] demonstrated that smoking cessation treatment can be added to treatment for drug abuse. Elkader et al. in 2009 [14] showed that those who quit smoking cigarettes become more jovial and less restless or depressed and suggested that the two treatments can be combined. Contrarily, West et al. (15) noted that many treatment personnel will fully tolerate nicotine addiction among their patients as they see smoking as a coping mechanism for patients struggling with cravings for heroin and other hard drugs.

Nonetheless, it is clear that the elimination of nicotine dependency is crucial for the successful treatment of drug addiction.Doctors, clinicians and public health experts should become aware of the relationship between addiction to nicotine and opium derivatives in order to better provide for the social costs of public health. For the first time in Iran Heydari et al (16) showed that smoking cessation treatment with opium maintenance therapy had better outcome with less relapse. After that a challenge was started in health system to approve this new approach.

Since the many studies in this field were not utilized this research paper may represents the first research utilization on merging smoking cessation with drug abuse treatment nationally within the Islamic Republic of Iran in support of parallel treatment of dual addictions.

\section{METHOD}

This was a cross-sectional study was done from 2012 to 2016. The results of clinical trial (16) were reported to Iran Drug Control Headquarters and Treatment Deputy of State Welfare Organization. However, due to the contradiction of these results to the health policies at that time several scientific and advisory meetings were held in these organizations during which similar foreign and updated documents were presented and the treatment method was defended.

In 2014 following the confirmation of this method in State Welfare Organization it was appointed to sign scientific memorandum of understanding between Treatment Deputy of State Welfare Organization and Tobacco Prevention and Control Research Center of Shahid Beheshti Medical Sciences University. It was also appointed to prepare common guidelines in order to provide the ground for running treatment programs. Then in 2015 it was appointed in the first phase to choose seven provinces of Tehran, Eastern Azerbayjan, Razavi Khorasan, Isfahan, Fars and Mazandaran for necessary trainings and starting to give smoking cessation services in substance abuse treatment centers. From each province four centers were chosen including two outpatient centers and two inpatient centers. Besides, 24 persons including both physicians and health care workers were chosen to take the related training courses and treatment guidelines. These centers have provided the services 
Research Utilization: An Experience of National Study on Merging Smoking Cessation With Drug Abuse Treatment in Welfare Organization, Iran 2017

since the beginning of June 2016 and all the new clients of substance abuse treatment were entered the survey. Clients with substance abuse treatment were entered the survey. Clients with severe psychotic disorders and having no family and specific address were omitted. All services were given free of charge including visit, assessment of tobacco smoking and its history, behavioral consultation and guidance to use nicotinic and non-nicotinic medications. Of course the State Welfare Organization dedicated some financial aids to these centers.

\section{FINDINGS}

2086 persons entered the study. All the participants were male. Their age average was $36.38 \pm 13.21$ years. 1213 person (58.14\%) consumed opium; 618 persons (29.6\%) consumed amphetamine; and the rest consumed more than one substance. All of them had the experience of tobacco smoking. 1627 persons (78\%) wanted to have simultaneous smoking cessation and they were satisfied. Among them 375 persons (23\%) could successfully quit smoking after six months and they were also in the procedure of substance abuse maintenance treatment. For 748 persons (46\%) the harm reduction was about the reduction of tobacco smoking in half the amount of starting the study. But the smoking cessation was not achieved in 504 persons (31\%). All the colleagues in 24 centers were satisfied with this program and considered it as a fruitful program.

\section{DiscUSSION}

Utilization of the study's outcomes is an important issue which is mostly disregarded and finally the utmost point of a study brings about a report or a published article. Whereas the outcomes lead to some changes in policies and new services, the study will be fruitful. Our experience herein was merging smoking cessation course with the State Welfare's program which was happening for the first time across the nation. It happened following a clinical trial done in 2012. (16)

Since many studies have showed that (17-18) in maintenance treatment of substance abuse, smoking cessation could reduce the relapse rate of substance abuse and also it could promote the quality of life, so it is essential to employ this method. However, it wasn't taken seriously before the study of Heydari et al. (16) and there was a misbelieve that it was hard to take the cessation programs of smoking and substance abuse parallelly during the same period. It is exactly the same matter that was pointed out in Shoptaw study (19) in which many families believed that substance abuse quit was highly important and they accepted the consumption of tobacco products. Even the addiction therapists believed that their duty was just in realm of substance abuse and it was not about the whole realm of health. This belief was reported in the studies of Tacke (20).

In these circumstances the outcomes of study of Heydari et al. (16) brought about a new challenge to alter the quit addiction programs. Due to the outcomes of this study which showed that patients and their families were satisfied of simultaneous cessation of smoking and drug and also it caused some reduction in substance abuse and relapse, policy makers of addiction treatment were convinced of changing the programs. The exemplars of this experience are shown in the studies of Satre et al. (21) and Josef et al. (22).

In our experience, about $40 \%$ of substance abusers could reduce smoking to half the initial consumption. This trend is totally plausible because as seen in the studies of Reid et al. (23) and Myers and Brown (24) this phase could be beneficial for the patients' health and it made them ready for the next phase.

As it is seen in several studies (25) simultaneous smoking cessation with drug abuse treatment not only leads to negative consequences, but also it can be suggested for successful treatment of drug abuse. Besides, as it is demonstrated in the present study, this program can be generalized and developed in other provinces all across the nation. 
Research Utilization: An Experience of National Study on Merging Smoking Cessation With Drug Abuse Treatment in Welfare Organization, Iran 2017

Many documents in Iran show that tobacco control program are acceptable (26-28) and many smoking cessation methods are available (29-35) but this experience about merging smoking cessation with drug abuse treatment is newly coming and may have effective outcomes in future.

In conclusion research utilization of smoking cessation intervention was acceptable and can have a significant impact on the general health of drug abusers.

\section{REFERENCES}

1. Gilead S. Is smoking delay smoking averted? American journal of Public Health, 2003, 93:412-416.

2. Mathers CD, Loncar D. Projections of global mortality and burde $\mathrm{n}$ of disease from 2002 to 2030. PLoS Medicine, 2006, 3:e422.

3. Petro Ret al. Mortality from smoking worldwide. British Medical Bulletin, 1996, 52:12-21.

4. Mokri, A. Brief overview of drug abuse status in Iran.Archives of Iranian Medicine, 2002, 5:184-190.

5. Ziaaddini H, Meymandi MS, Zarezadeh AR. The prevalence and motivation of cigarette smoking among Kerman high school students. Iranian journal of Psychiatry, 2007, 2:41-45.

6. Samii W. Drug abuse: Iran's thorniest problem. Brown journalof World Affairs, 2003, 9:283-299.

7. Bao Y, Lian Z, Liu Z. An investigation of cigarette smoking behavior and nicotine dependence among Chinese opiate addicts. Addictive Behaviors, 2009, 34:955-958.

8. MelloN et al. Effects of heroin self-administration on cigarette smoking. Psychopharmacology, 1980, 67:45-52.

9. Frosch D Let al. Associations between tobacco smoking and il licit drug use among methadone-maintained opiate-depend ent individuals. Experimental and Clinical Psychopharmacology, 2000, 8:97-103.

10. Story J, Stark MJ. Treating cigarette smoking in methadone maintenance clients. journal of Psychoactive Drugs, 1991, 23:205-215.

11. WapfV et al. The barriers to smoking cessation in Swiss metha done and buprenorphine-maintained patients. Harm Reduc tion journal, 2008,5:10.

12. Stein MD, Anderson BJ, Niaura R. Smoking cessation patterns in methadone-maintained smokers. Nicotine \& Tobacco Re search, 2007, 9:421-428.

13. Reid MS et al. Smoking cessation treatment in community based substance abuse rehabilitation programs. journal Sub stance Abuse Treatment, 2008, 35:68-77.

14. Elkader AK et al. Methadone-nicotine interactions in metha done maintenance treatment patients. journal of Clinical Psy chopharmacology, 2009, 29:231-238.

15. West Ret al. Outcome criteria in smoking cessation trials: pro posal for a common standard. Addiction, 2005, 100:299-303.

16. Heydari $G$ et al, Dual Addictions, Parallel Treatments: Nicotine Replacement Therapy for Patients Receiving Methadone Treatment in Iran, EMHJ, 2013 Vol 19 No 3 supplement, s25-s31

17. Fiore MC et al. Treating tobacco use and dependence: 2008 up date. Clinical Practice Guideline. Rockville, MD, United States Department of Health and Human Services, Public Health Service, 2008. 
Research Utilization: An Experience of National Study on Merging Smoking Cessation With Drug Abuse Treatment in Welfare Organization, Iran 2017

18. Richter KP, Arnsten JH. A rationale and model for addressing tobacco dependence in substance abuse treatment. Substance Abuse, Treatment, Prevention and Policy, 2006, 1:23.

19. Shoptaw S et al. Smoking cessation in methadone mainte nance. Addiction, 2002, 97:1317-132 8.

20. Tacke $U$ et al. The effect of tobacco smoking on subjective symptoms of inadequacy ("not holding") of methadone dose among opiate addicts in methadone maintenance treatment. Addiction Biology, 2001, 6:137-145.

21. Satre DD, Kohn CS, Weisner C. Cigarette smoking and long-term alcohol and drug treatment outcomes: a telephone follow-up at five years. Am J Addict. 2007 Jan-Feb;16(1):32-7.

22. Joseph AM. Nicotine treatment at the Drug Dependency Program of the Minneapolis VA Medical Center. A researcher's perspective. J Subst Abuse Treat. 1993 Mar-Apr;10(2):147-52.

23. Reid MS1, Fallon B, Sonne S, Flammino F, Nunes EV, Jiang H, Kourniotis E, Lima J, Brady R, Burgess C, Arfken C, Pihlgren E, Giordano L, Starosta A, Robinson J, Rotrosen J. Smoking cessation treatment in community-based substance abuse rehabilitation programs. J Subst Abuse Treat. 2008 Jul;35(1):68-77. Epub 2007 Oct 24.

24. Myers MG1, Brown SA. A controlled study of a cigarette smoking cessation intervention for adolescents in substance abuse treatment. Psychol Addict Behav. 2005 Jun;19(2):230-3.

25. Lemon SC1, Friedmann PD, Stein MD. The impact of smoking cessation on drug abuse treatment outcome. Addict Behav. 2003 Sep;28(7):1323-31.

26. Heydari G et al, The Second Study on WHO MPOWER Tobacco Control Scores in Eastern Mediterranean Countries Based on the 2013 Report: Improvements over Two Years, Arch Iran Med. 2014; 17(9): $621-625$

27. Heydari G et al, WHO MPOWER tobacco control scores in the Eastern Mediterranean countries based on the 2011 report, EMHJ, 2013 Vol 19 No 4, 314-319

28. Heydari G et al, Comparison of tobacco control policies in the Eastern Mediterranean countries based on tobacco control scale scores, EMHJ, 2012 Vol 18 No 8, 803-810

29. Heydari G et all, Which form of nicotine replacement therapy is more effective for quitting smoking? A study in Tehran, Islamic Republic of Iran, East Mediterr Health J, 2012 Vol 18 No 10, 1005-1010.

30. Heydari G et all, Efficacy of Telephone Quit line for smokers: 12 months follow up results, Tannafos, Vol 10, No 3, 2011.

31. Heydari G et all, A Comparative Study on Tobacco Cessation Methods: A Quantitative Systematic Review, Int J Prev Med, 2014 Vol 5 No 6

32. Heydari G, Ebnahmadi A, Masjedi MR, Lando H. Utilization of a telephone interactive voice-response tobacco cessation support service in the Islamic Republic of Iran, East Mediterr Health J, 2014 Vol 20 No $5,254-259$

33. Heydari G, Ebnahmadi A, Masjedi MR, Lando H. Status and costs of smoking cessation in countries of the Eastern Mediterranean Region, East Mediterr Health J, 2012 Vol 18 No 11, 1102-1108 
Research Utilization: An Experience of National Study on Merging Smoking Cessation With Drug Abuse Treatment in Welfare Organization, Iran 2017

34. Heydari G, Ebnahmadi A, Masjedi MR, Lando H. Efficacy of Nicotine Patch in Combination with Trazodone in Smoking Cessation, Tannafos, Vol 9, No 3, Summer 2010

35. Heydari G et all, Quitting smoking with Varenicline: Parallel, Randomized Efficacy Trial in Iran, The International Journal of Tuberculosis and Lung Diseases, Volume 16, Number 2, February 2012

Citation: Gholamreza Heydari, Mohsen Roshanpajouh, Mehri Amiri, Behroz Almasinia, Parizad Sinaee. "Research Utilization: An Experience of National Study on Merging Smoking Cessation With Drug Abuse Treatment in Welfare Organization, Iran 2017 ". American Research Journal of Addiction and Rehabilitation; 1(1): $16-21$

Copyright (c) Gholamreza Heydari, Mohsen Roshanpajouh, Mehri Amiri, Behroz Almasinia, Parizad Sinaee. This is an open access article distributed under the Creative Commons Attribution License, which permits unrestricted use, distribution, and reproduction in any medium, provided the original work is properly cited.

American Research Journal of Addiction and Rehabilitation 